\title{
Alien versus native: The fight for free space
}

\section{Mary Catherine Gallagher}

\author{
School of Biological, Earth and Environmental Sciecnes, UCC
}

"The truth is: the natural world is changing. And we are totally dependent on that world. It provides our food, water and air. It is the most precious thing we have and we need to defend it." (David Attenborough)

\section{Invasive species}

It is easy to forget that we live on an island. Even though we have recently become a lot more aware of where our food comes from, we don't really think about how it gets to us. In Ireland, 95\% of our imports and exports are transported by ships, but it is not just cargo that these vessels can move. Plants and animals can grow on the outside of ships, or survive in ballast water, which keeps ships steady, but is almost like a travelling aquarium. It has been estimated that there are up to 10,000 species being moved around the world every day - Just in the ballast water of ships!

Only some of these species will survive the journey to a new region, and not all of those will be able to become established in their new environment. However, for those alien species that can survive in a new area, they have the potential to thrive. In the absence of their natural predators and competitors, these species can grow and reproduce at rates that allow them to outcompete native species and reduce native biodiversity. Scientists have described invasive species as one of the greatest threats facing ecosystems globally but what does that really mean and how can they impact our daily lives?

\section{Ecosystem services}

Ecosystems provide us with services which are vital to our survival and well being, but often go unnoticed. The air we breathe, the water we drink, the soil that we grow our food in and the pollination of our crops, are all provided by ecosystem services. Invasive species threaten these services, by reducing biodiversity through competition, changing the way our ecosystems work and the services they give us. Along with these ecological implications, invasive species can also have economic impacts. In the Black Sea, the accidental introduction of a predatory sea gooseberry (a small jelly-like animal) led to a depletion of anchovy fish stocks. The sea gooseberry was consuming the eggs and juvenile stages of the anchovies and also food which would have been eaten by the anchovies themselves. Not only did this change the structure of the ecosystem, but reduced the abundance of anchovies, depleting fish stocks, the value of the fishery and the number of people it employed. 


\section{My research}

My research is focused on an alien species of barnacle (Figure 1), which is native to Australia and New Zealand. It was introduced to European waters in the 1940s through shipping, and is now widespread on European coasts. It is only in recent decades that increases in its abundance have been recorded within its invaded range. This time lag has meant that little is known about how this species competes with native species and how its presence might alter ecosystem function. I am hoping to answer these questions, along with trying understand what the factors controlling the current northern and southern invaded range limits of this species are, and how future climate change might alter the abundance and distribution of this species in comparison to natives.
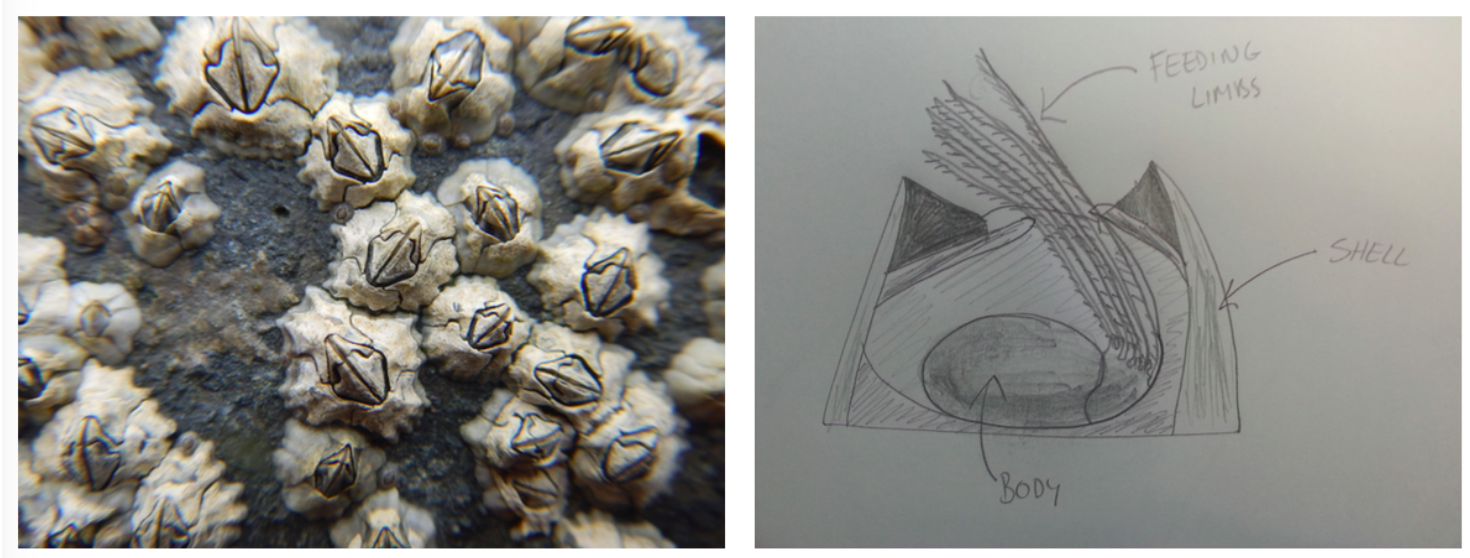

Figure 1: Photograph of study species (left) and drawing of barnacle structure (right) (Photograph and illustration are author's own).

\section{Why barnacles?}

Firstly, what is a barnacle? Have you ever been walking barefoot on rocks at the sea side, and felt something uncomfortable underfoot? When you look down you notice that the rocks are almost carpeted with very small shells - these are barnacles! Each of these shells is basically a house, with a little shrimp-like creature living inside, lying on its back. When the tide comes in, it kicks its legs into the water to grab food, through movable doors on top of the shell (Figure 1). They are amazing animals and Charles Darwin himself spent 8 years studying them - though apparently he was happy to move onto a new subject after that! Because barnacles are small, occur in large numbers and stay in one place, they have been used as "model" organisms for ecological studies. This is one reason why I chose to study an alien barnacle species. Also, it is thought that recent increases in the abundance of this alien species are due to environmental changes, in particular water temperature. My study species is warm water adapted, and it's possible that predicted increases in seawater temperature could promote the abundance of this, and other warm water alien species in our cold temperate waters. Potentially there could be many alien 


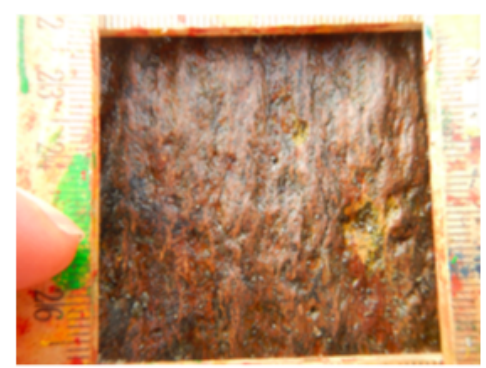

April 2014

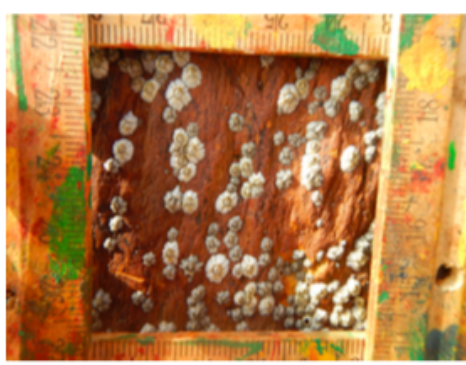

September 2014

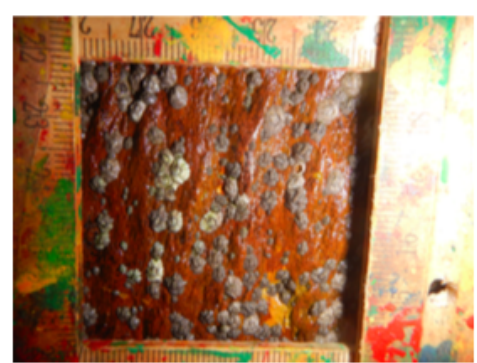

January 2015

Figure 2: Photographs of the same removal plot in April 2014, September 2014 and January 2015. The invasive species is visible in September 2014 and January 2015 as the grey coloured individuals, while the natives are more white in colour.

species lying dormant in our cold temperate waters, surviving but not becoming abundant until environmental conditions become more suitable for them.

\section{Marking your territory}

Space is a limited resource in lots of habitats, and the sea shore is no exception. The community composition of different areas is dependent on the outcomes of competitive interactions between different species. Invasive species are known to be able to rapidly make use of free space, helping them to become dominant in communities and to take over new structures placed in the marine environment, like piers and marinas. To gain a better understanding of how this invasive species competes with natives for space, I created experimental removal plots at seven different sites on the south-west coast of Ireland. These plots were scraped clear of all barnacles and scrubbed with wire wool to ensure that there were no animals left on the rock. Then I visited these sites, every month for over a year to see how the space was colonised over time.

\section{But first we take a selfie}

Each time I visited my field sites, I took photographs of each plot (Figure 2). Then, back in the office I analysed these images and compared them with those of the previous month to look at the survival of native and invasive individuals that had settled in the free space, count any new barnacles that had settled in the plots and also to measure their growth.

\section{Invasive versus native}

Lets take a closer look at the competitors and their strengths and weaknesses. When barnacles reproduce, they release their larvae into the sea and then after a time these larvae settle on hard surfaces on the shore. The invasive species has the potential to 
reproduce throughout the entire year. Individuals are able to produce multiple broods in one year and can become mature at just ten weeks old. On the other hand, for our two native species, breeding is restricted to specific times during the year (Spring and early Autumn), though they usually reproduce in large numbers. New native individuals, cannot reproduce the same year that they settle on the rocks.

As I started my study in the spring time, initially I recorded a native species in my plots. Then, after a couple of months, the invasive species began to establish and increase in abundance (Figure 2), followed by the second native species in early Autumn at some sites. Overall, the invasive species became the dominant barnacle in removal plots at four out of seven of my sites. However, when you look at the abundance of invasive species in relation to native species in the removal plots, compared with their abundances in the overall community at each site, providing free space only allowed the invasive species to become more abundant at three of the sites.

Even though the invasive species was dominant at most sites, the native species was still able to settle in the free space and survive. While, it is worrying that the invader dominated overall, it is interesting to see that it was not highly abundant at all sites, and that there are certain factors which inhibit its establishment at some locations. Looking at the starting community composition of my sites, it seems that the invasive species needs to be present in high abundances, to be able to dominate free space which becomes available. Even though invasive species are usually recognised as being superior competitors, I have found that is not always the case. The fact that native species were able to settle and survive in plots, even where the invader dominated, would suggest that it could be difficult for the invasive species to entirely outcompete and displace our native barnacle species.

\section{Here to stay}

There is no doubt that this invasive species is here to stay, however it seems that in many locations the native species are too! Evidence from my removal plots shows that even where the invader dominates, native species are capable of surviving too. However, the reverse was not true for sites with very high abundances of the native species. Although this invader is known to be able to rapidly settle on and dominate new structures in the marine environment, it is clear that timing is very important in this. If a new structure is built during the summer it will be dominated by the invasive species, but if it is built in the early spring, chances are it will initially be colonised by a native species, and then subsequently there would be settlement of the invader creating a more diverse community.

If there is a change in environmental conditions, like a change in temperatures, or a year where the native species fail to reproduce, it is possible that the invasive species will increase in abundance and displace native species. If this is the case, it could have worrying implications for the ecosystem. The larvae of barnacles provide an important food source for animals in the sea, including commercially important fish. If this invasive 
species outcompetes the native species, the abundance and timing of this food source would change, with implications higher up the marine food chain, changing biodiversity and ecosystem function! Thankfully this is not the case at the moment, as the native species remain dominant at some locations and are still present at most sites where the invader prevails. However, in order to ensure that this will still be the case in the future, it is important to try to conserve our native species and conditions which are favourable for their survival, helping them in the fight for free space against these alien invaders.

I would like to thank my supervisors Dr. Ruth Ramsay, Dr. Rob McAllen and Dr. Sarah Culloty. This PhD research would not be possible without funding provided by the NUI Travelling Studentship and the UCC Strategic Research Fund. 